direct suture. As a safeguard a drainage-tube was brought from the involved area out of a separate opening in the right flank. The parietal incision was sutured in three layers with chromic catgut. The patient made an uninterrupted recovery so far as the abdominal condition was concerned, the bowels were moved without medicine on the third day, she was well enough to be up at the end of a month and was out soon afterwards. The wound healed by first intention and appeared to be going on perfectly but at the end of the fifth week a chromic gut suture worked its way out followed by several others. This gave the patient more concern than any other part of her convalescence, though after this little episode terminated the scar was as strong and sound as could be desired.

On examining the parts removed I found that there was a small diverticulum on the cæcum just below the entrance of the ileum. On laying open the cæcum and colon the hard mass was found on the posterior wall of the latter just above the entrance of the ileum. It was composed of the indurated tissues surrounding a cavity beneath the mucous membrane but it felt very much softer than it did in situ. I therefore began to fear $I$ had removed bowel whose only crime was the harbouring of a simple ulcer. The cavity had a narrow mouth, so that it was not very obvious from the inside of the bowel, and its interior was about three-quarters of an inch in diameter and had sloughy walls. It lay in the submucous tissues and may have been lined by mucous membrane but ali traces of this had disappeared and no evidence of its presence was found on microscopical examination. I fully expected to find a foreign body as in the somewhat similar cases described by Bland-Sutton ${ }^{2}$ but there was none. On microscopical examination the wall of this cavity was found infiltrated with tubercle; a gland in the adjoining mesentery was carefully examined but showed no evidence of tubercle and there were no other ulcers or indurated areas in the parts removed to suggest further microscopical examination. The whole appearance suggested that a diverticulum had become infected with tubercle and at a later stage with sepsis. The presence of the diverticulum at the extremity of the cacum would support this view, for they are usually multiple, but I did not notice diverticula on the other parts of the colon incidentally exposed during the operation.

It is an interesting fact that there were no signs of tubercle elsewhere and that the patient has very much improved since the operation. A careful consideration of this case leads me to think that the course of events was somewhat as follows. A diverticulum became infected with tubercle and as a consequence became ulcerated. The contents could not be regularly removed by the actions of the bowel and decomposition arose. Thus to the tubercle sepsis was added and the acute symptoms were coincident with the onset of inflammation. The oedema of the retrocolic tissues clearly showed the presence of acute infection, for it is a constant attendant of sepsis in the vicinity. Though, strictly speaking, the ulcer was in the colon and not in the cæcum, it may probably be as accurately described as an example of typhlitis with commencing perityphlitis as many others that have been suffered to bear this nomenclature. If we consider the septio factor in this case as the important feature it may be looked upon as an example of a rare condition, since it is certain that typhlitis and its complications are, in the great majority of cases, due to disease originating in the appendix. Still, cases of true perityphlitis not of appendicular origin do occasionally occur and an example from perforation of the cæcum by a pin has come under my notice. From another point of view the case is interesting. for it shows how sometimes the addition of sepsis to tubercle may serve a useful purpose by drawing attention to the disease at a time when the local manifestation at least can be efficiently dealt with, just as a tuberculous ulcer in the appendix may rupture, so bringing on itself the ban of surgical interference. ${ }^{3}$ Further, the case is a useful reminder of the need for care in the diagnosis of swellings about the cæcal region. The diagnosis of appendicitis is more often correct than that of any other abdominal disease and this is so much realised that any other suggestion is apt to be treated with but scant courtesy.

Witbin the last two years I have seen a couple of cases

2 The Lancet, Oct. 24th, 1903, p. 1148

3 For cases see Lockwood, Appendicitis : its Pathology and Surgery, p. 154, and Some Surgical Aspects of Appendicitis, Northumberland and Durham Medical Journal, 1903, by G. Grey Turner. very similar to the one here recorded. In both there was a history suggestive of appendicitis and both were diagnosed as such, but in both a hard mass in the cæcal region turned out to be malignant disease of the bowel. It is not always easy to make the distinction and I have more than once overstepped the mark and diagnosed malignant disease or tubercle of the cæcum when the disease was inflammatory and originated in the appendix. Both malignant disease and tubercle may exactly mimic appendicitis but it should give rise to suspicion when in a middle-aged person mild attacks are associated with the presence of a very definite hard lump ; if a well-marked lump is found at the outset of an attack; if such a lump gets larger without becoming more tender; if there is evidence of intestinal obstruction, or if there has been much loss of weight. Of course, in any case of a suspicious mass in this neighbourhood an operation for its elucidation and treatment should not be delayed. I have elsewhere drawn attention to the several ways in which malignant bowel growths may simulate appendicitis and they may be briefly summarised as follows.

1. A growth in the cæcum may be associated with attacks like appendicitis. These attacks may be due to obstruction or to inflammation of the parts around and this may go on to the formation of an abscess which may exactly simulate one due to appendicitis.

2. A growth in any part of the large intestine beyond the cæcum may get blocked and if there is a competent ileocæcal valve the cæcum is the first part to feel the stress of the obstruction and at first all the pain is referred to this region. It is only as the attack passes off that the falling distension enables the lump elsewhere to be felt.

3. Primary malignant disease of the appendix may be the cause of the symptoms.

Newcastle-upon-Tyne.

\section{A CASE OF PRIMARY SUPPURATIVE PAROTITIS.}

BY J. WALTER CARR, M.D. LOND., F.R.C.P. LOND., PHYSICIAN TO THE ROYAI FREE HOSPITAL AYD TO THE VICTORIA HOSPITAL FOR CHILDRET, CHELSEA.

THE following case appears to be sufficiently exceptional to be worthy of record. The patient was a man, aged 79 years, who had suffered from several attacks of acute articular gout and of gouty eczema affecting the hands. About eight years ago he had double iridectomy performed for glaucoma. During the last year or two his urine had been abundant and of low specific gravity, averaging 1010, so that there was probably some granular change in the kidneys, but no albumin had ever been found. For several months before his last illness he had, for his age, been remarkably well and vigorous, both physically and mentally. During July last he underwent an unusual amount of exertion and excitement in connexion with a Royal visit to bis native city, but did not appear in any way the worse for it. Two days after this visit, on July 15th, he consulted his medical man, Dr. 'T. Mason Johnson of Pendletion, Manchester, on account of a painful swelling of the left side of the face which he had first noticed that morning. This rapidly extended and on the following day the patient was evidently seriously ill. On the evening of the 17th I saw him in consultation with Dr. Johnson and Dr. J. Dixon Mann of Manchester. There was then a large, tense, brawny swelling, exactly limited to the region of the left parotid gland; the skin over it was very orlematous but it was only slightly tender on pressure, much less so than it had been on the previous day, a result, perhaps, of the patient's increasing mental apatby, for he was only semi-conscious, his tongue was dry, his urine contained a good deal of albumin, and his temperature was $101^{\circ} \mathbf{F}$. There were, in short, all the indications of marked toxæmia. Next morning (July 18th) Mr. F. A. Southam of Manchester saw the patient with a view to operation, but as no fluctuation could be made out and the general symptoms seemed distinctly better it was decided to postpone making any incision. Glycerine and belladowna were applied to the swelling and strychinine, perchloride of iron, and brandy given internally. The improvement was maintained for the next two days; the mental condition kecame much clearer, the tongue moister, the albumin disappeared from 
the urine, and food was well taken. The temperature in the mouth varied between $99 \cdot 6^{\circ}$ and $101^{\circ}$, and the pulse from 80 to 90 . The local condition remained about the same. On the 21 st the patient was evidently not so well and a little thin pus was noticed to be escaping from the left ear. $\mathrm{Mr}$. Southam again saw him and although still unable to detect fluctuation advised immediate operation. This, however, was unavoidably delayed until the following day and by that time the patient's condition was one of extreme gravity ; he was almost completely unconscious, the temperature had risen to $102^{\circ}$, and the rapid breathing, with abundant small crepitations, especially at the base of the left lung, indicated the development of hypostatic pneumonia, or even of a more acute pneumonic process. Nevertheless, as a last chance, gas and oxygen were given, and Mr. Southam made a short incision into the gland just below the line of its duct. No definite abscess cavity was opened but the whole gland was in a breaking down condition and infiltrated with pus. Fluid injected through the incision escaped in part through the external auditory meatus. A considerable quantity of the gland substance was scooped out and a drainagetube was inserted. There was very little hæmorrhage. The patient never recovered consciousness after the operation, his breathing became increasingly rapid, and he died early the following morning, the temperature rising to $106 \cdot 6^{\circ}$ shortly before the end. It was noteworthy that throughout the illness there was no severe pain on opening the mouth or on masticating, such as is usually present in cases of mumps.

In the entire absence of any evidence of primary disease elsewhere the case must be regarded as one of acute primary parotitis, analogous, presumably, to acute pancreatitis, with which gland the parotids have anatomically so many points in common. In both, such an acute primary inflammation, especially leading to suppuration, is very rare, particularly so in the case of the parotids. A secondary parotitis, suppurative or non-suppurative, is met with fairly frequently although its exact causation has given rise to considerable controversy. It occurs after certain operations, usually in connexion with the abdomen or pelvis, and in association with some of the acute specific fevers and with various pyrmic and septic conditions, especially after parturition; but judging from the very scant references in medical literature and also from the experience of the four medical men who saw the patient, the primary disease must be altogether exceptional. At first the possibility of mumps was considered, but the patient's age, ${ }^{1}$ the absolute limitation of the disease to one gland, the brawny character of the swelling with marked cdema of the skin over it, and the severity of the constitutional symptoms were sufficient taken altogether to exclude this disease. A gouty form of parotitis has been described by Dr. Debout d'Estrées of Contrexéville, ${ }^{2}$ but would seem to be excessively rare and probably never leads to suppuration. The disease in this case was almost certainly microbial in origin and the question arises how the yland became infected; presumably from the mouth, zi $i \hat{a}$ Stenson's duct. There was, however, no obvious cause of sepsis in the month; the patient had had all his own teeth extracted many years before, not even a single stump being left and wore a complete set of artificial teeth, which appear to have been kept perfectly clean. On examination, however, of the inside of the mouth a rounded swelling of about the size of a small pea was felt close to the orifice of Stenson's duct, if not actually orer it; it did not feel like a calculus and was most likely a cyst. Very probably it hindered the escape of saliva and so led to a condition which facilitated the ascent of microbes, in the way so well described by Mr. C. J. Bond in his address on Ascending Currents in Mucous Canals and Gland Ducts and their Influence on Infection at the last meeting of the British Medical Association at Leicester. The intensely virulent character of the process was probably due largely to its oscurrence in an old man with damaged kidneys and consequent greatly diminished resistive power to microbial infection.

A case of primary parotitis recently recorded ${ }^{3}$ was shown to be due probably to a pneumococcal infection, but the patient was only 55 years of age, had a distinctly septic

1 An undoubted case of mumps in a woman, 75 years of age, is recorded (Brit. Med. Jour., vol. i., 1896, p. 1543), but the case is perhaps recorced (Brit. Med. Jour., vol. 1., 1896, p. 1543), but the case is perhaps 317 .

3 The LANCET, August 12th, 1905, p. 434. mouth, and the inflammation quickly subsided without going on to suppuration.

One may perhaps regret that in my case an incision into the gland was not made sooner, but on the whole I am disposed to think that this would not not have averted the fatal issue, as even a few hours before death there was no definite abscess cavity to drain and consequently it does not seem likely that the passage of toxic products into the blood which led to the fatal toxæmia would have been materially prevented.

Cavendish-place, $\mathrm{w}$.

\section{A CASE OF CONGENITAL HYPERTROPHIC} STENOSIS OF THE PYLORUS: TREATMENT BY GASTRIC LAVAGE WITH COMPLETE RECOVERY.

BY A. J. BLAXLAND, M.B. LoND., M.R.C.S. ENG., L.R C.P. LOND.

HOUSE PHYSICIAN AT THE HOSPITAL FOR SICK CHILDREN, GREAT ORMOND STREET.

CONSIDERING the diverse opinions held with regard to the treatment of hypertrophic stenosis of the pylorus in infants it may be of service to record in some detail a case in which complete recovery followed careful dieting and lavage of the stomach.

In an exhaustive article on this subject published in THF LANCET of March 11th Dr. G. F. Still strongly advocates in all cases a trial of stomach washing before resorting to such radical treatment as dilatation of the pylorus, pyloroplasty, or gastro-enterostomy, which must always be a very serious undertaking in an infant, especially in one who bas become marasmic from inability to absorb his food. If medical treatment fails and operation becomes necessary, lavage combined perhaps with nasal feeding will, as Dr. Still urges in his article, in nearly every case, however despcrate, have produced some temporary improvement and so increase the chance of a successful operation.

It does not at present appear possible to determine from the amount of wasting or vomiting, or from the size or hardness of the pyloric tumour, whether a given case will respond to medical treatment or not until the effect of such treatment is tried. It is therefore probable that the degree of spasm of the pylorus (if such it be) varies very greatly in different subjects. It is possible, in the case that I am now recording, since improvement so quickly followed on treatment, that the morbid condition was not very extensive, but the physical signs would lead one to believe otherwise.

The patient, a boy, aged four months, was admitted into the hospital on Feb, 17th, 1905, under the care of Dr. Garrod, for vomiting, wasting, and constipation. The child at birth, following a nine months' pregnancy and a normal labour, was in apparently perfect health and weighed ten pounds. He was not put to the breast but was given diluted cow's milk and went on quite well for a fortnight, at the end of which time he began to vomit and to lose weight. The vomiting occurred at moderately long intervals and was of a very forcible character. Large quantities-two or three feeds-were vomited at a time. A medical man was called in and various foods were tried-Nestlé's milk, Horlick's malted milk, Mellin's food, and "humanised " milk -all without success, and he was taken to the hospital at the age of four months, his weight then being eight pounds. The child was the last of eight, two of whom died in infancy from meningitis and the others were quite healthy and strong.

On admission the little patient was found to be considerably wasted, the skin was shrunken, and the expression was anxious. The tongue was clean. The abdomen, a little shrunken in, showed w. ll-marked peristalsis in the area of the stomach which could be brought out by flicking the abdominal wall. This peristalsis passed in slow waves from left to right and divided the stomach into two or three portions, each of about the size of a small Tangerine orange. On gentle but deep palpation a hard, elongated lump of about half the size of the terminal phalanx of the litile finger could be felt midway between the umbilicus and the right costal margin. This lump, not always palpable, could often be filt to form under 